Dunaetz, D. R., Smyly, C., Fairley, C. M., \& Heykoop, C. (2020). Values congruence and organizational commitment in churches: When do shared values matter? Psychology of Religion and Spirituality. Advance online publication. http://dx.doi.org/10.1037/rel0000314 (Preprint, not the definitive version)

\title{
Values Congruence and Organizational Commitment in Churches: When Do Shared Values Matter?
}

\author{
David R. Dunaetz, Carly Smyly, Carmen M. Fairley, and Colleen Heykoop \\ Azusa Pacific University
}

\begin{abstract}
Leaders and attenders of many churches may feel a tension between contemporary values of Western culture and more conservative values that have traditionally been held by many churches. Discrepancies in values may cause some people to leave their churches. This paper examines the relationship between values congruence (between church attenders and their churches) and organizational commitment, specifically, affective organizational commitment which measures one's emotional attachment to an organization (i.e., their church). In this study, church attenders $(\mathrm{N}=252$ ) provided information about themselves (concerning their personal values, their affective organizational commitment to their church, and demographics) and information about their churches (concerning the church's values and size). The values measured included both behavioral (tolerance of homosexuality) and cognitive (agreement with evangelical doctrine) aspects. The results indicate that affective organizational commitment to one's church is positively correlated with values congruence; no evidence was found that affective organizational commitment was correlated to the other variables measured. Further exploratory analyses indicated that this relationship between values congruence and affective organizational commitment varied with both the values of the church and the size of the church. In more conservative churches and in smaller churches, values congruence was more strongly related to affective organizational commitment than in more liberal churches and larger churches.
\end{abstract}

Keywords: church, values congruence, organizational commitment, megachurches, conservativism

As a dominant culture's values evolve (Mesoudi, Whiten, \& Laland, 2006), leaders of religious organizations may sense a tension between traditional, typically more conservative values, promoted by the religious organization and the more progressive values held by some of its members. Similarly, progressive leaders of religious organizations may create tension by promoting values that are not congruent with the values of some of the organizations' members. Such tensions may be disturbing to individual members and threaten the stability of the religious organization due to loss of membership. What is the relationship between values congruence and organizational commitment of attenders of contemporary North American churches, and what conditions influence this relationship?

Values congruence in organizational psychology is part of person-organization fit (Kristof, 1996; O'Reilly, Chatman, \& Caldwell, 1991; Posner, 2010), the degree to which a person fits into an organization in a mutually beneficial way. Rather than focusing on a global system of values such as Rokeach's (1973) terminal values (desirable end states) and instrumental values (modes of behavior by which one achieves the desired end states) or universal values found in all cultures, such as Schwartz's (1992) basic human values, the values congruence literature (Kristof, 1996; Verquer, Beehr, \& Wagner, 2003) typically focuses on the values that are salient in a particular organizational context, comparing the participants' beliefs and values to what they perceive the organization to believe and value.

Greater values congruence is associated with outcomes that benefit both the organization and the member of the organization, who, in most studies, is an employee. The organization benefits from better work performance, lower turnover, and more pro-social behaviors from the employee (Kristof-Brown, Li, \& Schneider, 2018; Kristof-Brown, Zimmerman, \& Johnson, 2005). The employee benefits from greater job satisfaction, greater organizational commitment, greater trust in supervisors, and greater satisfaction with coworkers, as well as fewer turnover intentions and lower stress (Kristof, 1996; Verquer et al., 2003). It is possible that some of the relationships exist in an equivalent form in religious organizations composed of voluntary members, such as churches.

Organizational commitment, the attachment that one has for an organization (A. Cohen, 2013; Meyer \& Allen, 1991) is an especially important concept associated with values congruence. It tends to reflect a member's global evaluation of an organization. Greater organizational commitment predicts greater job satisfaction, work motivation, job performance, work engagement, pro-social behavior, and occupational commitment (Meyer, Stanley, Herscovitch, \& Topolnytsky, 2002; Naquin \& Holton, 2002; Riketta, 2002). Affective organizational commitment (Meyer \& Allen, 1991), one's “emotional attachment to an organization" (Mercurio, 2015, p. 389), is an especially useful construct because it tends to be the best predictor of the above phenomena compared to the other dimensions of organizational commitment (Mercurio, 2015; Meyer et al., 2002). Unlike constructs measuring a sense of belonging in churches (e. g., Krause \& Bastida, 2011), affective organiza- 
tional commitment reflects a broad concept of emotional attachment to an organization, not limited to the attachment that comes from a sense of belonging or community. Although organizational members tend to self-select out of an organization based on their perceptions of poor fit, the degree of perceived fit of those remaining is likely to be one of many factors that influence their affective commitment to the organization (Schneider, Smith, \& Goldstein, 2000).

\section{Hypotheses}

This study examines the relationship between values congruence and affective organizational commitment among individuals who attend churches. It hypothesizes that, as in non-religious organizations, values congruence between individuals and their churches will be positively correlated with affective organizational commitment. Furthermore, exploratory analyses will be conducted to examine if this relationship is moderated by the demographic characteristics of the individual, by the personal values of the individual, or by the characteristics of the church including its size and values. This may help answer the question, "When do shared values in churches matter?"

\section{Method}

People who attend church regularly responded to an online survey which measured the variables in the hypothesis and those used for the exploratory analyses. This study was approved by the Institutional Review Board of the authors' university. Participants responded to items measuring their own values and items measuring the values of their church.

\section{Participants}

A convenience sample was recruited from the authors' social networks, all of which included a high percentage of church attenders, typically protestant from a variety of backgrounds. To ensure sufficient statistical power, a sample size of 278 was sought which yielded usable data from $N=252$ participants from 11 states $(69.9 \%$ from California and 3 individuals from outside the United States); participants who had little or no variance in their responses were excluded (e.g., those who marked the same extreme scores for all the reversed scored and nonreversed scored items of the same scale). Participants were $66.4 \%$ female with an average age of 41.54 years $(S D=13.54)$. Participants self-identified as White (71.4\%), Asian (14.7\%), Hispanic (11.5\%), Black (11.1\%), and other (1.6\%), while some preferred to not state $(2.4 \%)$; participants were allowed to choose multiple races or ethnicities.

\section{Measures}

Affective Organizational Commitment. Participants responded to eight statements using a 7-point Likert scale $(1=$ Strongly Disagree, $7=$ Strongly Agree) adapted from Meyer and Allen's (1991) Affective Organizational Commitment scale. The items were modified to measure affective organizational commitment to a church rather than to a place of employment. Items included "I would be very happy to spend the rest of my life with this church" (originally "I would be very happy to spend the rest of my career with this organization") and "I enjoy discussing my church with people outside it" (originally, "I enjoy discussing my organization with people outside of it"). The coefficient of reliability was very good $(\alpha=.88)$.

Personal Values. Participants indicated their personal values (using a 7-point Likert scale as above) by responding to seven items measuring moral and doctrinal values (Driedger, 1974). Three statements measured their personal moral values concerning individuals with non-traditional sexualities who attend their church (such as "I believe that it is okay for members of our church to be married to someone of the same sex") and four statements measured their doctrinal values based on the National Association of Evangelicals' (2018) definition of evangelical (such as "I believe that only those who trust in Jesus Christ alone as their Savior receive God's free gift of eternal salvation"). The scores for the seven items were recoded so that low scores indicated liberal values (tolerance of non-traditional sexualities and disagreement with evangelical doctrine) and high scores indicated conservative values (rejection of nontraditional sexualities and agreement with evangelical doctrine). A composite score indicating personal values was computed from the average of the seven items. The coefficient of reliability was very good $(\alpha=.84)$.

Church Values. The values held by attenders' churches were calculated like the personal values except each of the seven statements began with "my church believes. . ." rather than "I believe ..." A composite score similar to personal values was created with higher scores indicating more conservative churches and lower scores indicating more liberal churches. The coefficient of reliability was good $(\alpha=.75)$.

Values Congruence. The absolute value of the difference between personal values and church values was calculated as a measure of congruence between an individual and his or her church. Using the absolute value of a difference is a standard approach to measuring how well individuals fit into an organization (Kristof, 1996). This score was recoded so that $0=$ lowest congruence and $6=$ complete congruence of values between a participant and his or her church.

Size of Church. Participants indicated the size of their church from choosing from 8 ranges of attendance, for example, $1=$ less than $20,5=201-500$, and $8=$ more than 2,000 . The participants' median church size was 501-1000 attenders.

The intercorrelations and descriptive statistics for all the variables are shown in Table 1.

\section{Results}

\section{Principal Hypothesis.}

The hypothesis that values congruence in churches would predict affective organizational commitment was supported, $r(250)=.19, p=.0012$, one-tail. This is less than the average correlation reported in the meta-analyses examining person-organization fit (e.g., values congruence) and organizational commitment by Verquer et al. (2003), $r=.22$, and by KristofBrown (2005), $r=.42$. This difference suggests that moderators of this relationship might exist.

\section{Exploratory Analyses.}

Exploratory analyses were conducted to detect possible moderators of the relationship between values congruence and affective organizational commitment. To test for moderation, 
Table 1

Descriptive Statistics and Correlations

\begin{tabular}{|c|c|c|c|c|c|c|c|}
\hline & 1 & 2 & 3 & 4 & 5 & 5 & 7 \\
\hline 1. Affective Organizational Commitment & -- & & & & & & \\
\hline 2. Personal Values & .10 & -- & & & & & \\
\hline 3. Church Values & -.08 & $.62 * * *$ & -- & & & & \\
\hline 4. Values Congruence & $.19 * *$ & $.69 * * *$ & .02 & -- & & & \\
\hline 5. Size of Church & .07 & .05 & $.19 * *$ & -.07 & -- & & \\
\hline 6. Age & .03 & $.28 * * *$ & .06 & $.24 * * *$ & -.10 & -- & \\
\hline 7. Sex & .00 & -.02 & .02 & .02 & .00 & $-.13 *$ & -- \\
\hline$M$ & 5.11 & 5.09 & 5.69 & 5.15 & 5.79 & 41.54 & 1.66 \\
\hline$S D$ & 1.27 & 1.30 & .96 & .88 & 2.03 & 13.54 & .47 \\
\hline Range & $1.38-7$ & $1-7$ & $1-7$ & $1.96-6$ & $1-8$ & $18-82$ & $1-2$ \\
\hline
\end{tabular}

Note: ${ }^{*} p<.05,{ }^{* *} p<.01,{ }^{* *} p<.001$, two-tailed. $N=252$. For sex, $1=$ male and $2=$ female

multiple linear regression analyses were performed using values congruence, the potential moderator, and the interaction term (values congruence $\times$ potential moderator) to predict affective organizational commitment (J. Cohen, P. Cohen, West, $\&$ Aiken, 2003). The interaction term was not significant for personal values $(B=.076, p=.26$, two tails), age $(B=-.003, p$ $=.62$, two tails $)$, or $\operatorname{sex}(B=-.11, p=.57$, two tails $)$. However, size of church was a significant moderator $(B=-.12, p=.019$, two tails; $\left.\Delta R^{2}=.021, p<.001\right)$ of the relationship between values congruence and affective organizational commitment; a simple slopes analysis indicated that for churches $1 S D$ above the mean size, the unstandardized simple slope was .086 $(p=$ .48 , two tails) and for churches $1 S D$ below the mean size, the unstandardized simple slope was .55 ( $p<.001$, two tails; see Figure 1a). This means the relationship between values congruence and affective organizational commitment was stronger in small churches than in large churches where such a relationship might not, in fact, exist.

Similarly, church values significantly moderated $(B=.30, p$ $=.0029$, two tails; $\left.\Delta R^{2}=.034, p<.001\right)$ the relationship between values congruence and affective organizational commitment (See Figure 1b); ; a simple slopes analysis indicated that for churches $1 S D$ above the mean in conservative values, the unstandardized simple slope was .51 $(p<.001$, two tails) and for churches $1 S D$ below the mean in conservative values, the unstandardized simple slope was -.072 ( $p=.62$, two tails). This means the relationship between values congruence and affective organizational commitment was stronger in more conservative churches than in more liberal churches where such a relationship might not, in fact, exist.

Among the possible moderators examined, none were significantly correlated with affective organizational commitment. However, personal values, $r(250)=.69, p<.001$ (two tails), and age, $r(238)=.24, p<.001$ (two tails), were both significantly positively correlated with values congruence.

\section{Discussion}

This online, correlational study supported the hypothesis that values congruence, a form of person-organization fit, predicted greater affective organizational commitment in churches. Furthermore, supplementary exploratory analyses indicated that this relationship was moderated by the size of the church and by the church's values. Specifically, the relationship was stronger in smaller churches and in more conservative churches than in larger churches and more liberal churches.
This is the first study to demonstrate that the relationship between values congruence, a form of person-organization fit, and affective organizational commitment, a measure of a person's emotional attachment to the organization, occurs in religious organizations. Understanding this relationship provides insights concerning the mega-church phenomenon and for leaders of churches of all sizes.

Von der Ruhr and Daniels (2012) proposed a model of megachurches in which the commitment and cost required of attenders is initially low at such churches (compared to smaller churches) until the attender decides that he or she fits (defined as general match of the attender's tastes and preferences with what the church offers), at which point, the church's expectation for commitment rises. Von der Ruhr and Daniels (2012) were only able to provide general, preliminary data to support this model, using data with churches as the unit of analysis. This present study provides support for the model by demonstrating that larger churches have a greater fraction of people attending them who do not share their values but who have relatively high affective organizational commitment than do smaller churches. Moreover, this study shows that values congruence increases with the age of the attender. Further research may indicate whether this phenomenon is a result of attenders eventually adopting their churches' values, older attenders having enough experiences with churches to find a community with which they share values, or simply because churches have values that are more congruent with those of Generation $\mathrm{X}$ and Baby Boomers than with those of Millennials and Generation $\mathrm{Z}$.

Similarly, this study informs religious leaders that the values congruence of church members may not be related to their affective organizational commitment, especially in larger and more liberal churches. Many of the most emotionally attached members may share few of the church's values. In a church that is defined by beliefs and values (e.g., one which emphasizes a confession of faith in their identity), a weak or non-existent relationship between values congruence and commitment, as in larger or more liberal churches, may indicate that people are attending the church for reasons other than which the leadership believes. However, it is possible that the weakness of the relationship is due to a restriction of range resulting from the self-selection of members who remain associated with their church; the average values congruence was high, 5.15 on a $0-6$ scale. Future research can look for mediators of this relationship to better understand it. Intrinsic religiosity (Gorsuch, 1994) is a possible candidate since it is a measure of the degree 


\section{A. Moderation by church size}

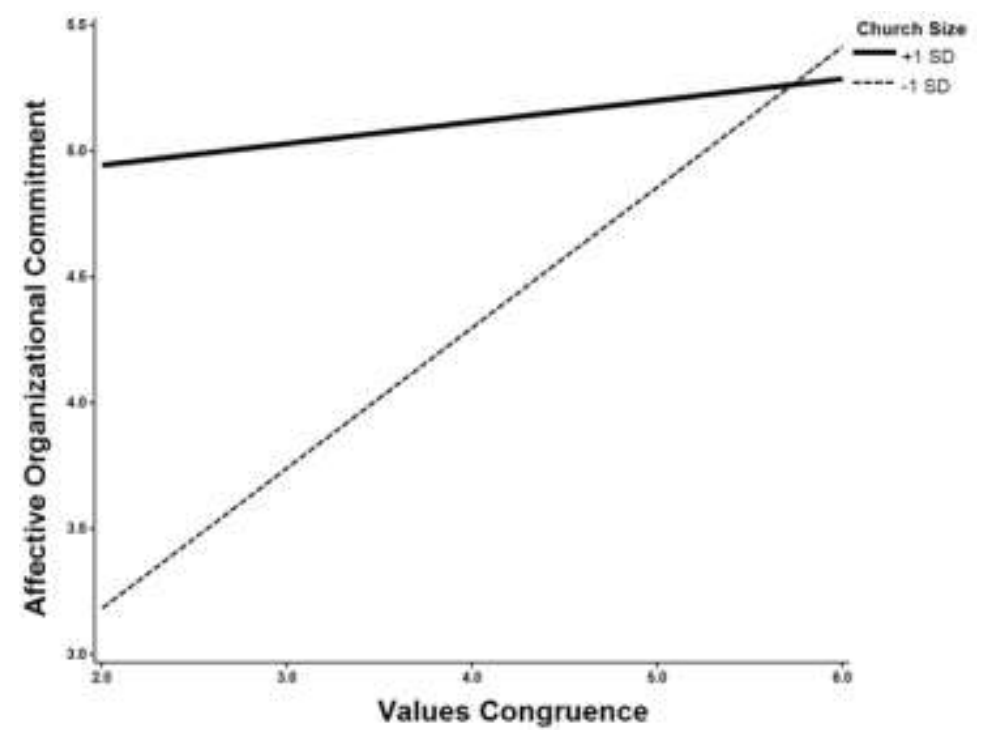

B. Moderation by church values

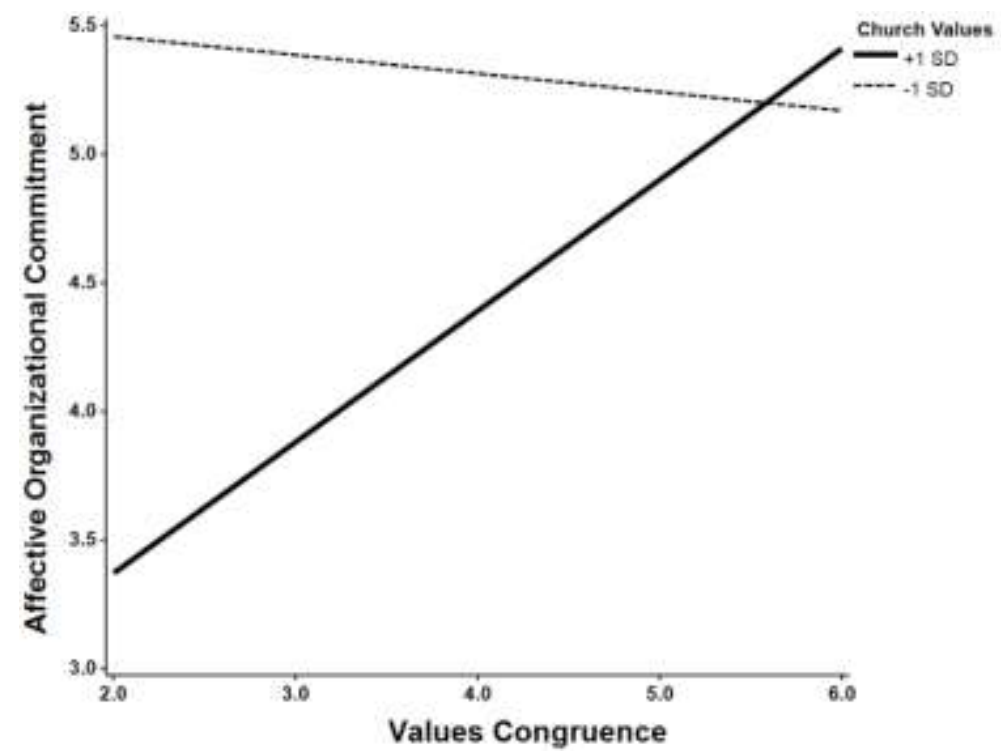

Figure 1. Moderation of the relationship between values congruence and affective organizational commitment by a) church size, and b) church values (higher scores = more conservative church values).

to which individuals have internalized religious values. People more strongly motivated by their religious values are more likely to be concerned about values congruence than those less motivated by religious values. Similarly, some form of extrinsic religiosity may motivate people to attend a church when values congruence is low.

Since all data about the churches, including church values, were collected from participants who also reported their own values, another limitation is that common method variance may have influenced the results. However, by calculating values congruence from the absolute value of a difference, some of this variance might have been reduced (Kristof, 1996).

The tension between contemporary values and traditional religious values is not likely to disappear. This study has demonstrated that emotional commitment to a church is, in general, related to the degree of congruence in values of church attenders and their churches. In response to the question, "When do shared values matter?", this study has shown that shared values 
are most important in smaller churches and more conservative churches because, in these contexts, the relationship between values congruence and affective organizational commitment is the strongest.

\section{References}

Cohen, A. (2013). Organizational commitment theory. In E. H. Kessler (Ed.), Encyclopedia of management theory (Vol. 2, pp. 526529). Los Angeles, CA: Sage Publications.

Cohen, J., Cohen, P., West, S. G., \& Aiken, L. S. (2003). Applied multiple regression/correlation analysis for the behavioral sciences (Third ed.). Mahwah, NJ: Lawrence Erlbaum.

Driedger, L. (1974). Doctrinal belief: A major factor in the differential perception of social issues. The Sociological Quarterly, 15, 66-80.

Gorsuch, R. L. (1994). Toward motivational theories of intrinsic religious commitment. Journal for the Scientific Study of Religion, 33, 315-325.

Krause, N., \& Bastida, E. (2011). Church-based social relationships, belonging, and health among older mexican Americans. Journal for the Scientific Study of Religion, 50, 397-409.

Kristof-Brown, A. L., Li, C. S., \& Schneider, B. (2018). Fitting in and doing good: A review of person-environment fit and organizational citizenship behavior research. In P. M. Podsakoff, S. B. MacKenzie \& N. P. Podsakoff (Eds.), The Oxford handbook of organizational citizenship behavior (pp. 353-370). New York, NY: Oxford University Press.

Kristof-Brown, A. L., Zimmerman, R. D., \& Johnson, E. C. (2005). Consequences of individuals' fit at work: A meta-analysis of person-job, person-organization, person-group, and person-supervisor fit. Personnel Psychology, 58, 281-342.

Kristof, A. L. (1996). Person-organization fit: An integrative review of its conceptualizations, measurement, and implications. Personnel Psychology, 49, 1-49.

Mercurio, Z. A. (2015). Affective commitment as a core essence of organizational commitment: An integrative literature review. Human Resource Development Review, 14, 389414.

Mesoudi, A., Whiten, A., \& Laland, K. N. (2006). Towards a unified science of cultural evolution. Behavioral and Brain Sciences, 29, 329-347.
Meyer, J. P., \& Allen, N. J. (1991). A three-component conceptualization of organizational commitment. Human Resource Management Review, 1, 61-89.

Meyer, J. P., Stanley, D. J., Herscovitch, L., \& Topolnytsky, L. (2002). Affective, continuance, and normative commitment to the organization: A meta-analysis of antecedents, correlates, and consequences. Journal of Vocational Behavior, 61, 2052.

Naquin, S. S., \& Holton, E. F. (2002). The effects of personality, affectivity, and work commitment on motivation to improve work through learning. Human Resource Development Quarterly, 13, 357-376.

National Association of Evangelicals. (2018). What is an evangelical? Retrieved from https://www.nae.net/what-is-anevangelical/

O'Reilly, C. A., III, Chatman, J., \& Caldwell, D. F. (1991). People and organizational culture: A profile comparison approach to assessing person-organization fit. Academy of Management Journal, 34, 487-516.

Posner, B. Z. (2010). Another look at the impact of personal and organizational values congruency. Journal of Business Ethics, 97, 535-541.

Riketta, M. (2002). Attitudinal organizational commitment and job performance: A meta-analysis. Journal of Organizational Behavior, 23, 257-266.

Rokeach, M. (1973). The nature of human values. New York, NY: Free Press.

Schneider, B., Smith, D. B., \& Goldstein, H. W. (2000). Attractionselection-attrition: Toward a person-environment psychology of organizations. In W. B. Walsh, K. H. Craik \& R. H. Price (Eds.), Person-environment psychology: New directions and perspectives (pp. 61-85). Mahwah, NJ: Lawrence Erlbaum Associates Publishers.

Verquer, M. L., Beehr, T. A., \& Wagner, S. H. (2003). A meta-analysis of relations between person-organization fit and work attitudes. Journal of Vocational Behavior, 63, 473-489.

von der Ruhr, M., \& Daniels, J. P. (2012). Examining megachurch growth: Free riding, fit, and faith. International Journal of Social Economics, 39, 357-372. 